2020-07

\title{
Changes in fish communities due to benthic habitat shifts under ocean acidification conditions
}

Cattano, C

http://hdl.handle.net/10026.1/15586

10.1016/j.scitotenv.2020.138501

Science of The Total Environment

Elsevier BV

All content in PEARL is protected by copyright law. Author manuscripts are made available in accordance with publisher policies. Please cite only the published version using the details provided on the item record or document. In the absence of an open licence (e.g. Creative Commons), permissions for further reuse of content should be sought from the publisher or author. 
2 This is the author's accepted manuscript. The final published version of this work (the version of 3 record) is published by Elsevier in Science of the Total Environment. The manuscript was made 4 available online on the 5 April 2020 at

5 https://www.sciencedirect.com/science/article/pii/S0048969720320143?via\%3Dihub This work is 6 made available online in accordance with the publisher's policies. Please refer to any applicable terms 7 of use of the publisher.

\section{Changes in fish communities due to benthic habitat shifts under 9 ocean acidification conditions}

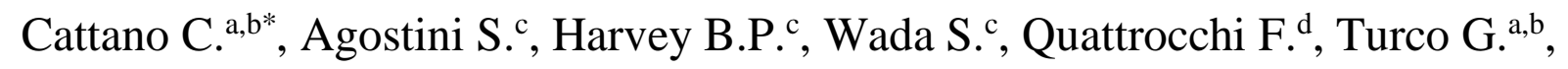
Inaba K. ${ }^{c}$, Hall-Spencer J.M. ${ }^{\text {ce }}$, Milazzo M. ${ }^{\text {a,b }}$

a Department of Earth and Marine Sciences (DiSTeM), University of Palermo, via Archirafi 20-22, 90123 Palermo, Italy

${ }^{\mathrm{b}}$ CoNISMa (Interuniversity Consortium of Marine Sciences), Piazzale Flaminio 9, 00196 Rome, Italy

${ }^{\mathrm{c}}$ Shimoda Marine Research Center, University of Tsukuba, 5-10-1 Shimoda, 415-0025 Shizuoka (Japan)

d IRBIM - Istituto per le Risorse Biologiche e le Biotecnologie Marine, CNR - National Research Council, Via Luigi Vaccara 61, 91026, Mazara del Vallo (TP) (Italy)

${ }^{\mathrm{e}}$ Marine Biology and Ecology Research Centre, University of Plymouth, Plymouth, PL4 8AA (UK)

* Corresponding author: cattancarlo@gmail.com 


\section{Abstract}

Ocean acidification will likely change the structure and function of coastal marine ecosystems over coming decades. Volcanic carbon dioxide seeps generate dissolved $\mathrm{CO}_{2}$ and $\mathrm{pH}$ gradients that provide realistic insights into the direction and magnitude of these changes. Here, we used fish and benthic community surveys to assess the spatio-temporal dynamics of fish community properties off $\mathrm{CO}_{2}$ seeps in Japan. Adding to previous evidence from ocean acidification ecosystem studies conducted elsewhere, our findings documented shifts from calcified to non-calcified habitats with reduced benthic complexity. In addition, we found that such habitat transition led to decreased diversity of associated fish and to selection of those fish species better adapted to simplified ecosystems dominated by algae. Our data suggest that near-future projected ocean acidification levels will oppose the ongoing range expansion of coral reef-associated fish due to global warming.

Keywords: carbon dioxide, biogenic habitat complexity, scleractinian coral cover, reef-associated fish

\section{Introduction}

Shifts in marine biogenic habitats in response to anthropogenic activities and a range of stressors have been documented since the 1960s (Hughes 1994). In tropical coral reef ecosystems examples include studies of the impacts of overfishing (Jackson et al. 2001), outbreaks of coral-eating predators (De'ath et al. 2012), diseases (Hughes 1994), pollution (McCulloch et al. 2003), hurricanes (Hughes 1994), and extreme temperatures (Hoegh-Guldberg 1999). Ocean warming is changing coastal marine communities, for example due to (1) warm-water species (e.g. corals and tropical fish) moving poleward following their thermal physiological niche, (2) changes in the strength of interspecific interactions (e.g. increase of herbivory from warm-water fish leading to the loss of kelp forests at their low latitude limits), and (3) a decrease in biogenic habitat complexity (e.g. Vergès et al. 2014, 2016; Hall-Spencer \& Harvey 2019). Ocean Acidification (OA), the alteration of seawater carbonate chemistry due to rising atmospheric $\mathrm{CO}_{2}$ concentrations, adds an extra set of stressors to those caused by warming. Meta-analyses show that 
decreased seawater $\mathrm{pH}$ due to OA may impair calcification and accelerate dissolution for many calcifying habitat-formers, while rising $p \mathrm{CO}_{2}$ levels may enhance the primary production and carbon fixation rates of non-calcifying autotrophs (Falkenberg et al. 2013; Harvey et al. 2013; Kroeker et al. 2013; Wittmann and Pörtner 2013). As a result, there will be losers and winners under OA conditions, with effects on ecosystems documented along gradients in seawater $\mathrm{pH}$ at $\mathrm{CO}_{2}$ seeps around the world (e.g., HallSpencer et al. 2008; Fabricius et al. 2011) including reductions in habitat complexity, shifts in competitive interactions and changes in species dominance.

While $\mathrm{CO}_{2}$ seeps are not perfect analogues for ocean acidification (e.g., Fabricius et al. 2017), they nevertheless comprise one of the very few field-based tools available to assess OA effects on ecosystems and communities-(Hall-Spencer and Harvey 2019). To date, our knowledge about the ecosystem effects of $\mathrm{OA}$ is advancing rapidly with increasing evidence from temperate (Hall-Spencer et al. 2008; Nagelkerken et al. 2015; Milazzo et al. 2019), subtropical (Agostini et al. 2018) and tropical (Fabricius et al. 2011, 2014; Inoue et al. 2013; Enochs et al. 2015) $\mathrm{CO}_{2}$ seeps. The responses of biogenic habitats to OA differ regionally. Shifts from diverse to depauperate scleractinian species assemblages and from hard to soft coral communities have been observed in Papua New Guinea (Fabricius et al. 2011), Palau (Barkley et al. 2015) and in Southern Japan (Inoue et al. 2013). As carbon dioxide levels increase, there is a shift in community dominance from corals to seaweeds in the Northern Mariana Islands (Enochs et al. 2015) and at a subtropical-temperate transition zone in Japan (Agostini et al. 2018). How such OAinduced habitat shifts affect fish requires further study as most work at $\mathrm{CO}_{2}$ seeps to date at has focused on bacteria, algae and invertebrates (Hall-Spencer et al. 2008; Fabricius et al. 2014; Sunday et al. 2017; Milazzo et al. 2019).

Very few attempts have been made to estimate the effects of OA-induced habitat simplification on fish communities (Munday et al. 2014; Nagelkerken et al. 2015, 2017). A study at three $\mathrm{CO}_{2}$ seeps in Papua New Guinea reported reduced coral reef complexity at elevated $\mathrm{CO}_{2}$ respect to control sites. However, 
there was no difference in fish species richness between seep and control sites, and no difference in fish community structure at two out of the three seep-control groups examined (Munday et al. 2014). The only slight differences detected in fish community structure were mostly driven by small-bodied fish species showing strong habitat preferences (Munday et al. 2014). In another paper, Nagelkerken et al. (2015) documented shifts from kelp/macroalgae and seagrass to low-relief turf-algae at temperate $\mathrm{CO}_{2}$ seeps that seemed to cause a loss of fish predators and predatory release of prey fish species, even though their antipredator responses were compromised.

At present, how ocean warming and acidification will affect ecosystem properties and functioning is still under debate. Some modelling attempts suggest that declines in aragonite saturation state $\left(\Omega_{\text {arag }}\right)$ will limit the poleward expansion of tropical coral reefs that is underway due to ongoing warming (Yara et al. 2012; van Hooidonk et al. 2014), as will insufficient light in winter for coral algal symbiont photosynthesis (Muir et al. 2015).

Here, we evaluate the temporal consistency of changes in fish communities in response to biogenic habitat shifts off $\mathrm{CO}_{2}$ seeps located in the NW Pacific (Japan), in a region that has naturally low levels of $p \mathrm{CO}_{2}$, high carbonate saturation levels and elevated local seawater temperatures (Midorikawa et al. 2005). These conditions allow the coexistence of both canopy-forming macroalgae and scleractinian coral communities at ambient $\mathrm{CO}_{2}$ conditions, while a transition to low-relief algal turf habitats occurs at elevated $\mathrm{CO}_{2}$ levels (Agostini et al. 2018; Harvey et al. 2019). To assess how fish community properties changed spatially along the $\mathrm{pCO}_{2}$ gradient, we coupled fish and benthic community assessments (habitat complexity, canopy height, and \% cover), along a $\mathrm{CO}_{2}$ gradient and at control sites off Shikine Island (Eastern Japan). The study was carried out over two time periods (June and September) to investigate whether the effects of OA-mediated habitat shifts on fish community composition and structure are temporally consistent, specifically when acute seasonal typhoons (usually from July to September), may affect benthic community structure and habitat complexity. In addition, we carried out 
fish trait comparisons between the different $\mathrm{CO}_{2}$ sites, to assess changes in taxonomic richness and abundance of fish subdivided by geographic distribution (Tropical, Subtropical and Temperate), trophic guilds (Carnivore, Omnivore, Herbivore and Planktivore) and affinity to coral reef habitats.

We expected that fish communities would change in composition and structure as a result of decreasing habitat complexity along a spatial $\mathrm{CO}_{2}$ gradient and that these changes would be consistent over time. Since it has been suggested that OA may decrease overall habitat complexity (e.g. from complex corals and canopy-forming algae to low-profile algae and turfs; Sunday et al. 2017), we expected that fish community species richness would decrease with increasing levels of $\mathrm{CO}_{2}$. As $\mathrm{CO}_{2}$ enrichment acts both as a stressor for scleractinian corals and as a substrate for primary producers, we also expected that the number of species of fish from tropical and subtropical origins would decrease, while the diversity of herbivorous fish would increase in elevated $\mathrm{CO}_{2}$ conditions.

\section{Materials and Methods}

\subsection{Study sites and carbonate chemistry}

Shikine is a volcanic island east of the Izu peninsula in Japan $\left(34^{\circ} 19^{\prime} 9^{\prime \prime} \mathrm{N}, 139^{\circ} 12^{\prime} 18^{\prime \prime}\right.$ E) with many $\mathrm{CO}_{2}$ seeps in shallow waters. Based on previous geochemical investigations (Agostini et al. 2015), our survey locations were selected to avoid potentially confounding geochemical factors (e.g. high sulfides, negative redox potential, altered total alkalinity and elevated temperature). One location (Elevated-CO was within Mikawa Bay and a second location (Control) characterised by ambient $\mathrm{CO}_{2}$ conditions was positioned in an adjacent bay with similar depths (3-12 m), and exposure to wind and currents (Fig. 1).

To document spatial variation in the carbonate chemistry, a WQC24 multi-parameter logger (DKK-TOA Corporation, Tokyo, Japan) and a HydroC® $\mathrm{CO}_{2}$ II sensor (Contros System \& Solutions GmbH, Germany) were deployed between 9:00 am and 3:00 pm by scuba divers along four and five 100-m 
122

123

124

125

126

127

128

129

130

131

132

133

134

135

136

137

138

transects in the Elevated- and Control $\mathrm{CO}_{2}$ locations, respectively (Fig. 1). Every 10 meters the seawater $\mathrm{pH}\left(\mathrm{NBS}\right.$ scale), temperature $\left(\mathrm{T},{ }^{\circ} \mathrm{C}\right)$, salinity, and depth $(\mathrm{m})$ were recorded for 5 minutes with the DKKTOA, whilst the HydroC® $\mathrm{CO}_{2}$ II sensor recorded measures of $p \mathrm{CO}_{2}$ ( $\mu$ atm) every 5 seconds. The $\mathrm{CO}_{2}$ sensor detects dissolved $\mathrm{CO}_{2}$ molecules that diffuse through a thin film composite membrane into an internal gas circuit containing a detector chamber where the $p \mathrm{CO}_{2}$ is determined by means of an IR absorption spectrometer. Both loggers were positioned at 1 meter from the sea-bottom at an average depth range of 3-12 meters, and were attached to a floating buoy equipped with a GPS (eTrex30x, Garmin) to record the exact position of each measurement. Total alkalinity (TA) was measured from seawater samples collected underwater at each location ( $N=24$ in June; $N=25$ in September). Water samples were immediately filtered at $0.45 \mu \mathrm{m}$ using disposable cellulose acetate filters (Dismic, Advantech, Japan) and stored at room temperature in the dark (for no more than one week) until measurement. TA was measured by titration (TiTouch i915, Metrohm) with $\mathrm{HCl}$ at $0.1 \mathrm{~mol}^{-1}$, and calculated from the Gran function between $\mathrm{pH} 4.2$ and 3.0. The titrations were cross-validated using a working standard (SD: $\pm 9 \mu \mathrm{mol} \mathrm{kg}{ }^{-1}$ ) and against certified reference material purchased from the A.G. Dickson laboratory (Batch 152). The $\mathrm{CO}_{2} \mathrm{SYS}$ software (Pierrot et al. 2006) was used to calculate $p \mathrm{CO}_{2}$ (Table 1) from T, pH, salinity and TA values, and to control in situ continuous measurements of $p \mathrm{CO}_{2}$ recorded by the HydroC® $\mathrm{CO}_{2}$ II sensor. The disassociation constants from Mehrbach (1973), as adjusted by Dickson and Millero (1987), $\mathrm{HSO}_{4}$ using Dickson (1990), and total borate concentrations from Uppström (1974) were used for carbonate chemistry calculations (Table 1). The HydroC® $\mathrm{CO}_{2}$ II sensor was not employed in the September survey due to logistic constrains.

The carbonate chemistry measurements along the nine $100-\mathrm{m}$ transects were used to identify five sampling $\mathrm{CO}_{2}$ sites in the rocky subtidal zone between 3 and $12 \mathrm{~m}$ depth in Mikawa bay and the Control bay: one 'High- $\mathrm{CO}_{2}$ ' (High), one 'Mid- $\mathrm{CO}_{2}$ ' (Mid) and one 'Low- $\mathrm{CO}_{2}$ ' (Low), and two 'Ambient- $\mathrm{CO}_{2}$ ' 
145 (Ref 1 and Ref 2; Fig. 1; Table 1). In each $\mathrm{CO}_{2}$ site, both the benthic habitats and the fish communities

146 were characterised as detailed below.

147

148

Table 1 - Seawater chemistry of the subtidal sampling sites off Shikine Island. Values from June and September 149 surveys are reported as mean $( \pm S D)$. Minimum (Min) and maximum (Max) $\mathrm{pCO}_{2}$ values are also reported. $150 p \mathrm{CO}_{2}$ calc. $=p \mathrm{CO}_{2}$ levels calculated with CO2SYS. $p \mathrm{CO}_{2}$ meas. $=p \mathrm{CO}_{2}$ levels measured with the HydroC@ $151 \mathrm{CO}_{2}$ II logger.

\section{a) June 2016}

\begin{tabular}{|c|c|c|c|c|c|c|c|c|c|}
\hline $\begin{array}{c}\mathrm{CO}_{2} \\
\text { location }\end{array}$ & $\begin{array}{l}\mathrm{CO}_{2} \\
\text { site } \\
\end{array}$ & Salinity & $\mathbf{T}^{\circ} \mathbf{C}$ & $\begin{array}{l}\text { pH } \\
\text { nbs } \\
\end{array}$ & n (pH) & $\begin{array}{c}\text { TA }(\mu \mathrm{mol} \\
\left.\mathrm{kg}^{-1}\right)\end{array}$ & $\begin{array}{c}p \mathrm{CO}_{2} \text { calc. } \\
(\mu \mathrm{atm})\end{array}$ & $\begin{array}{c}p \mathrm{CO}_{2} \text { meas. } \\
(\mu \mathrm{atm})\end{array}$ & $\begin{array}{c}\mathrm{n}\left(p \mathrm{CO}_{2}\right. \\
\text { meas. })\end{array}$ \\
\hline Elevated & High & $\begin{array}{c}34.5 \\
(0.05)\end{array}$ & $\begin{array}{l}19.9 \\
(0.5)\end{array}$ & $\begin{array}{c}7.87 \\
(0.15)\end{array}$ & 11 & 2249.9 & $\begin{array}{c}971.7(434.0) \\
\text { Min:591.8 } \\
\text { Max:2062.1 }\end{array}$ & $\begin{array}{c}952.8(450.8) \\
\text { Min:567.7 } \\
\text { Max:2360.4 }\end{array}$ & 417 \\
\hline Elevated & Mid & $\begin{array}{c}34.6 \\
(0.07)\end{array}$ & $\begin{array}{l}19.4 \\
(0.5)\end{array}$ & $\begin{array}{c}8.09 \\
(0.05)\end{array}$ & 17 & 2253.4 & $\begin{array}{c}497.2(72.6) \\
\text { Min:373.8 } \\
\text { Max:645.8 }\end{array}$ & $\begin{array}{c}552.1(188.2) \\
\text { Min:368.2 } \\
\text { Max:1552.1 }\end{array}$ & 843 \\
\hline Elevated & Low & $\begin{array}{c}34.7 \\
(0.05)\end{array}$ & $\begin{array}{l}19.5 \\
(0.7)\end{array}$ & $\begin{array}{c}8.16 \\
(0.05)\end{array}$ & 16 & 2270.5 & $\begin{array}{c}404.9(54.8) \\
\text { Min:361.2 } \\
\text { Max:523.2 }\end{array}$ & $\begin{array}{c}402.1(53.4) \\
\text { Min:358.0 } \\
\text { Max:591.1 }\end{array}$ & 555 \\
\hline Control & Ref 1 & $\begin{array}{c}34.7 \\
(0.05)\end{array}$ & $\begin{array}{l}18.9 \\
(0.3)\end{array}$ & $\begin{array}{c}8.21 \\
(0.01)\end{array}$ & 28 & 2253.1 & $\begin{array}{c}348.2(10.6) \\
\text { Min:322.0 } \\
\text { Max:367.6 }\end{array}$ & $\begin{array}{c}347.9(13.9) \\
\text { Min:307.2 } \\
\text { Max:373.8 }\end{array}$ & 994 \\
\hline Control & Ref 2 & $\begin{array}{c}34.8 \\
(0.05)\end{array}$ & $\begin{array}{l}19.5 \\
(0.2)\end{array}$ & $\begin{array}{c}8.25 \\
(0.03)\end{array}$ & 27 & 2250.8 & $\begin{array}{c}311.5(29.3) \\
\text { Min:255.4 } \\
\text { Max:356.7 }\end{array}$ & $\begin{array}{c}311.8(29.1) \\
\text { Min:251.9 } \\
\text { Max:357.8 }\end{array}$ & 913 \\
\hline
\end{tabular}

\section{b) September 2016}

\begin{tabular}{|c|c|c|c|c|c|c|c|}
\hline $\begin{array}{c}\mathrm{CO}_{2} \\
\text { location }\end{array}$ & $\begin{array}{l}\mathrm{CO}_{2} \\
\text { site }\end{array}$ & Salinity & $\mathbf{T}^{\circ} \mathbf{C}$ & $\begin{array}{l}\text { pH } \\
\text { nbs }\end{array}$ & $\mathbf{n}(\mathbf{p H})$ & $\begin{array}{c}\text { TA }(\mu \mathrm{mol} \\
\left.\mathrm{kg}^{-1}\right)\end{array}$ & $p \mathrm{CO}_{2}$ calc. $(\mu \mathrm{atm})$ \\
\hline Elevated & High & $\begin{array}{l}33.9 \\
(0.1)\end{array}$ & $\begin{array}{l}26.0 \\
(0.1)\end{array}$ & $\begin{array}{c}7.65 \\
(0.09)\end{array}$ & 4 & 2267.8 & 1646.4 (397.3) Min:1220.9 Max:2026.5 \\
\hline Elevated & Mid & $\begin{array}{l}33.9 \\
(0.2) \\
\end{array}$ & $\begin{array}{l}25.1 \\
(1.0)\end{array}$ & $\begin{array}{c}7.91 \\
(0.12)\end{array}$ & 6 & 2257.3 & 849.7 (291.0) Min:524.4 Max:1372.0 \\
\hline Elevated & Low & $\begin{array}{l}33.9 \\
(0.0) \\
\end{array}$ & $\begin{array}{l}25.6 \\
(0.1) \\
\end{array}$ & $\begin{array}{c}8.13 \\
(0.01)\end{array}$ & 4 & 2269.3 & 459.3 (12.7) Min:442.7 Max:473.1 \\
\hline Control & Ref 1 & $\begin{array}{l}33.9 \\
(0.2)\end{array}$ & $\begin{array}{l}26.3 \\
(1.4)\end{array}$ & $\begin{array}{c}8.18 \\
(0.01)\end{array}$ & 4 & 2249.9 & 395.4 (11.9) Min:379.3 Max:407.8 \\
\hline Control & Ref 2 & $\begin{array}{l}33.9 \\
(0.2)\end{array}$ & $\begin{array}{l}26.2 \\
(1.7)\end{array}$ & $\begin{array}{c}8.16 \\
(0.01)\end{array}$ & 4 & 2249.5 & 420.8 (13.6) Min:409.2 Max:439.8 \\
\hline
\end{tabular}

152 


\subsection{Benthic habitat characterisation}

Average canopy height and percentage cover (\% cover) of benthic taxa were recorded in the June and

September surveys along $25 \mathrm{~m}$ strip transects positioned in the five $\mathrm{CO}_{2}$ sites (High, Mid, Low, Ref1 and

Ref2). Specifically, four transects were deployed in the 'High- $\mathrm{CO}_{2}$ 'site (High), six transects within the

'Mid- $\mathrm{CO}_{2}$ ' (Mid) site, six transects within the 'Low- $\mathrm{CO}_{2}$ ' (Low) site, and nine transects each in the two 'Ambient $\mathrm{CO}_{2}$ ' sites (Ref1 and Ref2; Fig. 1). Within each $25 \mathrm{~m}$ benthic transect, the canopy height was measured every meter using the point-intercept method, and a Biotic Habitat Profile (BHP) ratio was estimated as a proxy of biotic complexity. BHP, conceptually similar to the well-established chain method, was calculated a posteriori by dividing the contoured distance following the measured canopy profile by the linear distance (i.e. 25 meters).

The $\%$ cover of benthic taxa was assessed in ten photoquadrats, positioned at ca. 5 meters apart along 166 each 25 meter transect. An Olympus Stylus Tough TG3 with a PT056 camera housing was mounted on a 1 x $1 \mathrm{~m}$ frame. The $\%$ cover was estimated using the open-access software Image-J (http://rsb.info.nih.gov/ij/; Schneider et al. 2012) by tracing the 2-dimensional outline of each benthic morphological taxon. For each photoquadrat the \% cover of the following benthic groups was recorded:

Turf algae, crustose coralline algae (CCA), Non-Canopy-forming fleshy algae ( $<5 \mathrm{~cm}$ canopy height), 171 Canopy-forming algae ( $\geq 5 \mathrm{~cm}$ canopy height), Caulerpa chemnitzia var. peltata, Table corals, Soft Corals, Encrusting Corals, Massive Corals (i.e. boulder corals with massive growth forms), Anemones and Sponges.

\subsection{Fish surveys}

176 Species composition and relative abundance of fish were visually censused within standard linear $25 \times 5$ 
September 2016, respectively. Fish transects were located haphazardly within each sampling $\mathrm{CO}_{2}$ site at

179 4-10 m depth, and were conducted between 09.00 am and $03.00 \mathrm{pm}$ by a scuba diver leaving behind a $25 \mathrm{~m}$ measure tape, while counting and identifying all the fish encountered $2.5 \mathrm{~m}$ either side of the tape (125 $\mathrm{m}^{2}$; Harmelin-Vivien et al. 1985). Water visibility exceeded $15 \mathrm{~m}$ for all counts. Each sampling day, only two spatially separated transects (at $>20 \mathrm{~m}$ distance each other) were gathered at each $\mathrm{CO}_{2}$ site to avoid temporal dependence of data (Stewart-Oaten et al. 1986).

To make trait-mediated comparisons among different $\mathrm{CO}_{2}$ conditions, the different fish species were also subdivided by geographical origin (Tropical, Subtropical and Temperate), by trophic guild (Carnivore,

Omnivore, Herbivore and Planktivore), and by their association with coral reefs (i.e. coral reef associated and non-associated species) following Nakamura et al. (2013) and FishBase (http://www.fishbase.org/).

\subsection{Data analyses}

Changes in benthic habitat composition among $\mathrm{CO}_{2}$ sites were analysed using non-metric multidimensional scaling technique (nMDS) and tested with Permutational Multivariate Analysis of Variance (PERMANOVA; Anderson and Braak 2003) using the software PRIMER 6 and PERMANOVA+ $\beta 3$ package (Clarke and Gorley 2006). The analysis was performed on Bray-Curtis measures in a multivariate context of untransformed \% cover data, using 9999 permutations of the appropriate units. Two fixed factors were considered: " $\mathrm{CO}_{2}$ site" with 5 levels (High, Mid, Low, Ref 1 and Ref 2) and "Season" with two 2 levels (June and September).

197 To identify the relevant variables characterising the benthic habitat which were responsible for the variation in fish community structure and composition, we used a Multivariate Distance Based Linear Model [DISTLM, Anderson et al. 2008]. Both the fish community and the benthic datasets were square root transformed and the step-wise model selection method based on the AIC criterion was performed to assess the benthic variables related with Bray-Curtis resemblance matrix of the fish dataset. To visualise 
202

203

204

205

206

207

208

209

210

211

212

213

214

215

216

217

218

219

220

221

222

223

224

the fish community data as a biplot, the Distance-based redundancy analysis (dbRDA; Legendre and Anderson 1999; McArdle and Anderson 2001) using the benthic variables identified by the DISTLM routine was used.

To investigate the potential relationship between $p \mathrm{CO}_{2}$ and habitat complexity (as BHP index, log transformed) we used an Additive Mixed Model (AMM) with a Gaussian distribution and the identity link. AMM was used because it allows for the modelling of the non-linear effects of continuous explanatory variables by incorporating smooth functions (Wood 2011). Specifically, the cubic regression spline was used as a one-dimensional non-parametric smoothing function and the number of knots $\mathrm{k}$ was set to 6 , to prevent the models from producing complex non-linear relationships of little biological significance (Wood 2006). To account for the lack of independence of the BHP data of the same Site per Season we used Site $\mathrm{x}$ Season as random intercept, which is assumed to be normally distributed with mean 0 and variance $\sigma^{2}$. Data for both sampling campaigns (June and September) were combined into a single data set and Season was modelled as a factor. The model was fitted using maximum likelihood (ML) parameter estimation. The analysis was performed using the R package 'mgcv' (Wood 2011).

We also used a method derived from meta-analysis to assess the effects of the different $\mathrm{CO}_{2}$ conditions on the number $(\mathrm{S})$ and abundance $(\mathrm{N})$ of fish species, also considering their classification by geographical distribution $\left(\mathrm{S}_{\text {origin }}\right)$, trophic guild $\left(\mathrm{N}_{\text {trophic }}\right)$ and coral reef association $\left(\mathrm{S}_{\text {coral }}\right)$. To this aim, we calculated the effect size (a metric that quantifies the difference between the control and experimental groups) as the response ratio, i.e. the natural logarithm of the ratio between the averaged response variable values

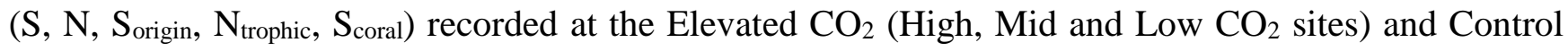
(Ref1 and Ref2 sites) locations. These analyses were performed using the R (R Core Team 2018) package 'metafor' (Viechtbauer 2010). 


\section{Results and Discussion}

Benthic communities changed from rocky habitats dominated by scleractinian corals and canopy-forming macroalgae to rocky reefs covered in low-profile and turf algae from Control (Ref1 and Ref2) to Elevated $\mathrm{CO}_{2}$ sites (Low, Mid and High) and this observation was consistent in both of the considered time periods (Fig. 2; PERMANOVA: $\mathrm{CO}_{2}$ site x Season, Pseudo-F=7781.2; $\mathrm{P}($ perm $\left.)=0.0001\right)$. Composition and structure of benthic communities did not differ between sites within ambient $\mathrm{CO}_{2}$ condition both in June (i.e., Ref1 = Ref 2; Pair-wise T test, $\mathrm{t}=1.52 ; \mathrm{P}($ perm $)=0.08)$ and September $($ Pair-wise $\mathrm{T}$ test, $\mathrm{t}=1.20$; $\mathrm{P}($ perm $)=0.28$ ) surveys, whilst they did significantly differ in most of the pair-wise comparisons of sites within the elevated $\mathrm{CO}_{2}$ sites (Table $\mathrm{S} 1$ ).

Table, massive and encrusting corals were common at control sites in both sampling periods. They are able to survive at this high latitude $\left(34^{\circ} \mathrm{N}\right)$ in the NW Pacific due to the warm northward flow of the Kuroshio Current (Veron and Minchin 1992). Hard corals were absent along transects taken at elevated $\mathrm{CO}_{2}$ conditions. In contrast to some other $\mathrm{CO}_{2}$ seep systems (Suggett et al. 2012; Inoue et al. 2013), soft corals were rare and were absent in our elevated $\mathrm{CO}_{2}$ transects. Instead, dense mats of Caulerpa chemnitzia var. peltata and the diatom Biddulphia biddulphiana covered most of the rocky substrata at the elevated $\mathrm{CO}_{2}$ sites in June. These species were not seen in our transects in September, often revealing a covering of crustose coralline algae or low profile turf algae on the rocks (Fig. 2). As recently suggested, this was likely due to strong wave energy during typhoon activity that occurs in summer and early autumn (from late July to early October each year) on Shikine Island (Harvey et al. 2019). This major seasonal habitat shift resulted in an overall loss of canopy height due to the increase in the abundance of a few low profile algal and turf species which may outcompete large and slow-growing species under ocean acidification conditions (Harley et al. 2012; O’Brien \& Scheibling 2018; Harvey et al. 2019). The ability of a few opportunistic species to withstand $\mathrm{OA}$ effects, benefit from $\mathrm{CO}_{2}$ enrichment and displace 
dominant habitat-forming species (such as canopy-forming algae or coral early stages), has been 250 previously documented (e.g. Connell et al. 2018; Agostini et al. 2018) and can be attributed to stunted successional development (Gaylord et al. 2015).

Previous $\mathrm{CO}_{2}$ seeps studies revealed both detrimental and no effects of elevated $\mathrm{CO}_{2}$ levels on the ecophysiological and behavioral performances of fish (e.g. Munday et al. 2014; Nagelkerken et al. 2015; Milazzo et al. 2016; Cattano et al. 2017; Di Franco et al. 2019). Here we focus on fish responses at the community level.

Fish assemblages changed significantly between sites along the $\mathrm{CO}_{2}$ gradient, and between elevated $\mathrm{CO}_{2}$ and reference sites. The DISTLM procedure revealed differences in fish assemblage composition and structure, and identified five variables that best explained such patterns: the table and massive corals, the turf, the non-canopy forming algae and the CCA. The dbRDA ordination of the dataset constrained by these variables showed that the difference in the fish communities along the $\mathrm{CO}_{2}$ gradient was best explained by turf, massive and non-canopy algae, while the differences between June and September were best explained by table corals and CCA (Fig. 3). Thus, the clear change of fish communities from ambient to elevated $\mathrm{CO}_{2}$ conditions was associated with a biogenic habitat shift under OA conditions.

To date, few studies have documented the effects of OA-induced habitat changes on the structure and composition of fish communities. Munday et al. (2014) found that fish communities differed little between $\mathrm{CO}_{2}$ seeps and nearby control reefs in Papua New Guinea, suggesting that such similarities were

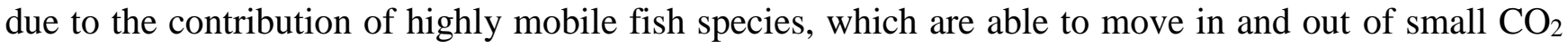
seep areas. The few observed differences in the abundance of certain fish species were related to coral community changes (from branched to massive corals) between $\mathrm{CO}_{2}$ exposed and un-exposed reefs (see Fabricius et al. 2014) rather than by the direct effects of high $\mathrm{CO}_{2}$ on fish. Nagelkerken et al. (2015) described habitat characteristics and fish species composition at two different $\mathrm{CO}_{2}$ seeps, documenting predator reductions and habitat shifts at elevated $\mathrm{CO}_{2}$ conditions, which together led to an increase of a 
273 few territorial fish species. A more recent study carried out off the White Island $\mathrm{CO}_{2}$ seeps in New

274 Zealand documented loss of fish diversity and homogenisation of fish communities under OA conditions,

275 suggesting that elevated $\mathrm{CO}_{2}$ indirectly boosted the abundance of a single species thus altering the

276 competitive relationships among species and suppressing the abundance of the competitive subordinates

277 (Nagelkerken et al. 2017). Contrary to these previous studies, where fish community differences between

$278 \mathrm{CO}_{2}$ exposed and unexposed reefs were evaluated focusing on a few species with narrow home ranges,

279 here we compared the structure and the composition of entire fish communities finding significant

280 differences among the four $\mathrm{CO}_{2}$ conditions considered.

281 The effects of OA on fish communities may depend on how elevated $\mathrm{CO}_{2}$ affects the different species

282 directly and indirectly. By altering acid-base balance and the processing of sensory information, elevated

$283 \mathrm{CO}_{2}$ concentrations affect physiological and behavioural performance in fish, although such effects are

284 species- and trait-specific (reviewed in Cattano et al. 2018). In addition, by promoting shifts in biogenic

285 habitat (Milazzo et al. 2019), habitat simplification (Sunday et al. 2017) and food web simplification

286 (Fabricius et al. 2014; Vizzini et al. 2017), high $\mathrm{CO}_{2}$ conditions may indirectly affect some fish species,

287 especially those with highly specialised habitat and resource use. Conversely, generalist species could

288 cope better with the predicted effects of OA on habitat and resources (e.g. Wilson et al. 2008a). This

289 inter-specific variability in the extent to which fish may respond to OA-driven habitat modifications

290 could play a role in shaping the direction of community shift and the composition of novel fish

291 communities under elevated $\mathrm{CO}_{2}$ conditions (Nagelkerken et al. 2017).

292 Our findings support the prediction that OA simplifies habitat composition and reduces habitat 293 complexity (Sunday et al. 2017). Biogenic habitat complexity (BHP) decreased with increasing $p \mathrm{CO}_{2}$

294 levels, in a non-linear relationship (Fig. 4a). When looking at model residuals including both seasons,

295 habitat complexity was high at $p \mathrm{CO}_{2}$ values below $\sim 500 \mu \mathrm{atm}$, whilst this relationship was significantly 296 negative for values up to $1000 \mu$ atm (i.e. decreased complexity with increasing $p \mathrm{CO}_{2}$ ), after which no 
significant effects were detected probably due to the low sample size (Fig.4b). Overall, this trend was consistent in the two sampling campaigns (Fig. 4c). The minimum index values were reached between $\sim 500$ and $\sim 1000 \mu \mathrm{atm}$, where table corals disappeared being replaced mainly by turf, non-canopy algae and Caulerpa chemnitzia var. peltata, and where the only calcifying groups were represented by CCA or a few encrusting corals. The consistent complexity reduction in the elevated $\mathrm{CO}_{2}$ sites compared to control conditions matches the habitat shift from corals and canopy-forming macroalgae to turf dominated reefs, which indeed provides fewer structure and habitat functions than corals (Filbee-Dexter and Wernberg, 2018). Such transition to less complex habitats may lead to the loss of a suite of resources for fish (e.g. food and space availability) and to the alteration of important ecological processes, such as foraging, settlement and predation avoidance. OA research in $\mathrm{CO}_{2}$ seeps has documented altered properties and non-linear responses for invertebrate communities along $\mathrm{CO}_{2}$ gradients (e.g. Fabricius et al. 2014; Milazzo et al. 2019), whilst no effects were detected in fish communities despite lower habitat complexity under elevated $\mathrm{CO}_{2}$ conditions (Munday et al. 2014).

Here for the first time, a consistent temporal response of the fish fauna to the OA-mediated habitat shift was documented. Overall, the number of species declined by $35 \%$ and $57 \%$ when comparing fish species richness at Control vs High $\mathrm{CO}_{2}$ sites in June and September, respectively (see Table S3). In addition, average species richness and abundance significantly decreased from Control to elevated $\mathrm{CO}_{2}$ conditions, with the lowest values recorded at the High and $\mathrm{Mid} \mathrm{CO}_{2}$ sites (Fig. 5a; Table S3). Such a pattern was consistent in both June and September (Fig. 5a; Table S3) and confirms previous evidence that shifts toward less complex habitat causes decreased fish diversity and abundance (e.g. Wilson et al. 2008b), as well as simplified and homogenised fish communities under OA conditions (Nagelkerken et al. 2017). ecosystems (Mouillot et al. 2013). Environmental alterations may not only lead to biodiversity loss, but also to changes in community function, through the selection of species with traits well-adapted to the 
321 new environmental conditions. Since functional groups may show specific habitat requirements and 322 preferences, the occurrence and abundance of certain species can be strongly influenced by habitat

323

324

325

326

327

328

329

330

331

332

333

334

335

336

337 composition and characteristics. As expected, trait-based comparisons of fish communities along the $\mathrm{CO}_{2}$ gradient reveal a change in composition towards fish species of less tropical and sub-tropical origin (Fig.

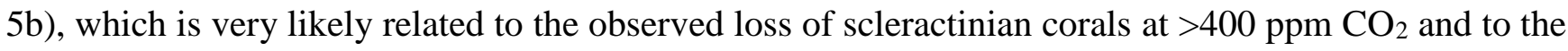
disappearance of the more specialised associated fish fauna they support. Therefore, the observed transitions from corals/high-profile algae to low-profile/turf algae support the available models suggesting that OA will hold temperature-induced poleward expansion of coral habitats (Yara et al. 2012), and this will cascade on the composition of the associated fish fauna with a decreasing pool of tropical, sub-tropical and coral reef associated species under elevated $\mathrm{CO}_{2}$ conditions. In this regard, Nakamura et al. (2013) documented an increase of warm-water tropical fish along the Japan high-latitude waters. Our findings rather suggest that if ongoing OA will act as a supplementary game-changer in the near future, this could not be the case.

When looking at fish trophic guilds we found that, relative to ambient $\mathrm{CO}_{2}$ conditions, the abundance of herbivorous fish was significantly higher at the High $\mathrm{CO}_{2}$ site in June, but not in September when seasonal typhoons caused the removal of macroalgal and turf cover particularly from the high $\mathrm{CO}_{2}$ area (Fig. 5c). Conversely, omnivorous species showed the opposite pattern being more abundant after the typhoon season. These results support previous evidence showing that an increased abundance of herbivore species at elevated $\mathrm{CO}_{2}$ conditions can be driven by the greater biomass of primary producers associated with enhanced nutritional quality (Vizzini et al. 2017). When turf and algae are removed by wave action, the availability and type of food changes, with repercussions on trophic guild composition (i.e. less herbivorous and more omnivorous species). In addition to this, results from recent experiments suggest that by increasing their macrophyte consumption and defecation rates, herbivore population growth could further modify trophic processes in benthic systems under OA conditions, hence amplifying 
345 detritus biomass production and potentially altering energy pathways and ecosystem functioning (Zarco346 Perello et al. 2019).

347 By contrast, a consistent decrease in the abundance of carnivore species was observed along the $\mathrm{CO}_{2}$ 348 gradient in both the sampling seasons (Fig. 5c). Such switches in the composition of functional groups 349 (i.e. increase of herbivore and reduction in carnivores) appears to be a common community property in elevated $\mathrm{CO}_{2}$ systems and has been described by other ecosystem studies carried out in temperate natural $\mathrm{CO}_{2}$ vent systems (Vizzini et al. 2017; Nagelkerken et al. 2015; Milazzo et al., 2019). In this regard, we speculate that piscivorous species may be attracted to more complex habitat characterised by higher prey abundance, while herbivores may prefer less complex areas where primary production is higher and this resource can be accessed more easily. We also found a consistent decline in the abundance of planktivorous fish and in the number of coral reef associated species from ambient to elevated $\mathrm{CO}_{2}$ conditions (Fig. 5c and 5d). Again, this seems to be related to the loss of coral species at the more elevated $\mathrm{CO}_{2}$ sites, which provide structural complexity and represent the preferred habitat for many coral fish species and their prey (Coker et al. 2014; Smith et al. 2016). Our findings add to previous evidence from ocean warming studies showing fish diversity declines following extensive coral loss due to bleaching events (e.g. Pratchett et al. 2011). In this regard, we suggest that OA may act as an additional bottleneck for fish community resilience under predicted ocean change scenarios. Natural analogues have many benefits for furthering knowledge about the responses of fish to OA conditions, but they are not perfect analogues for acidifying oceans. The seep areas are localised and so fish can move in and out, complicating dose-response assessments (Hurlbert 1984; Munday et al. 2014; Cornwall and Hurd 2015). Moreover, carbonate chemistry can be highly variable at $\mathrm{CO}_{2}$ seeps (Cattano et al. 2016; Cattano et al. 2017; Agostini et al., 2018) and toxic areas around volcanic vents need to be avoided in studies of the effects of ocean acidification (Vizzini et al. 2013). Nonetheless, the seeps allow studies of the ecosystem effects of $\mathrm{OA}$ and over time, using multiple $\mathrm{CO}_{2}$ seep locations, a pattern is 
beginning to emerge about the effects of OA on fish communities. An additional caveat with volcanic

$370 \mathrm{CO}_{2}$ seeps is that ocean acidification is occurring concurrently with warming, thus preventing their use

371

372

373

374

375

376

377

378

379

380

381

382

383

384

385

386

387

388

389

390

391

392 as analogues for future oceans (Rastrick et al. 2018). This issue can be addressed by assessing ecosystem

responses at $\mathrm{CO}_{2}$ seep in different biogeographic regions, or by manipulating temperature along $\mathrm{CO}_{2}$ gradients (Alessi et al. 2019), or by exploiting marine heat waves to assess the combined stress of rising temperature and elevated $\mathrm{CO}_{2}$ (Rodolfo-Metalpa et al. 2011). In this context, recent evidence combining laboratory, mesocosm and meta-analyses of $\mathrm{CO}_{2}$ seep research suggests that $\mathrm{OA}$ affects the outcome of ocean warming (Goldenberg et al 2018).

In summary, our data provide direct evidence that shifts in biogenic habitat and complexity reduction underpin a major loss (35-57\%) of marine fish diversity as levels of carbon dioxide in seawater increase in coastal waters off Japan. Ocean acidification is expected to limit the poleward range expansion of coral reef-associated fish that is now occurring due to warming in Japan (Yamano et al. 2011; Agostini et al 2018; Kumagai et al. 2018) and elsewhere (Baird et al. 2012; Serrano et al. 2013; Denis et al. 2015; Tuckett et al. 2017). By enhancing the competitive strength of algae at the expense of structurally complex calcifying organisms, such as corals, our surveys indicate that ocean acidification will change fish community function with a greater abundance of herbivorous fish species but fewer carnivores and planktivores. Such changes in fish communities would cause major changes in trophic processes and energy pathways, as well as affecting fisheries. We conclude that the indirect effects of rising $\mathrm{CO}_{2}$ levels on coastal ecosystems will have a profound impact on reef fish communities.

\section{Acknowledgements}

We would like to thank the technical staff of Shimoda Marine Research Center (University of Tsukuba) for field assistance and the use of RV Tsukuba, and Prof. Alessandro Aiuppa and Dr Rossella Di Napoli 
393 (University of Palermo, Italy) for providing the HydroC Carbon Dioxide Sensor. We are grateful to Prof.

394 Nakamura for help with fish identification. This study was supported by the 'International Education and 395 Research Laboratory Program', University of Tsukuba. Travel costs were funded by the University of 396 Palermo for C.C. and by a Japan Society for the Promotion of Science Short Term Invitation Fellowship 397 (Grant Number: S16073) and by JAMBIO for M.M.

398 Images used within the graphical abstract are courtesy of the Integration and Application Network, 399 University of Maryland Center for Environmental Science (ian.umces.edu/symbols/).

400 Author contributions

$401 \mathrm{CC}$ and MM conceived the experiment and wrote the first draft of the manuscript. CC, SA, BPH, 402 SW, KI, JH-S and MM carried out the sampling surveys. FQ and GT performed the statistical 403 analyses. All authors contributed to the latest version of the manuscript.

404 Competing financial interests

405

406 The authors declare no competing financial interests.

407 


\section{References}

410

411

412

413

414

415

416

417

418

419

420

421

422

423

424

425

426

427

428

429

430

431

432

433

434

435

436

437

438

439

440

441

442

443

444

Agostini S, Wada S, Kon K, Omori A, Kohtsuka H, Fujimura H et al. (2015) Geochemistry of two shallow $\mathrm{CO}_{2}$ seeps in Shikine Island (Japan) and their potential for ocean acidification research. Regional Studies in Marine Science, 2, 45-53.

Agostini S, Harvey BP, Wada S, Kon K, Milazzo M, Inaba K, Hall-Spencer JM (2018) Ocean acidification drives community shifts towards simplified non-calcified habitats in a subtropical-temperate transition zone. Scientific Reports, 8:11354.

Alessi C, Giomi F, Furnari F, Sarà G, Chemello R, Milazzo M (2019) Ocean acidification and elevated temperature negatively affect recruitment, oxygen consumption and calcification of the reefbuilding Dendropoma cristatum early life stages: Evidence from a manipulative field study. Science of The Total Environment, 693, 133476.

Anderson M, Braak CT (2003) Permutation tests for multi-factorial analysis of variance. Journal of statistical computation and simulation, 73(2), 85-113.

Anderson M, Gorley RNRN, Clarke K, Anderson MJ, Gorley RN, Clarke KR, Anderson M, Gorley R, Andersom MJ (2008) PERMANOVA+ for PRIMER. Guide to software and statistical methods.

Baird AH, Sommer B, Madin JS (2012) Pole-ward range expansion of Acropora spp. along the east coast of Australia. Coral Reefs, 31(4), 1063-1063.

Barkley HC, Cohen AL, Golbuu Y, Starczak VR, De Carlo TM, Shamberger KEF (2015) Changes in coral reef communities across a natural gradient in seawater $\mathrm{pH}$. Science Advances, 1, e1500328.

Cattano C, Giomi F, Milazzo M (2016) Effects of ocean acidification on embryonic respiration and development of a temperate wrasse living along a natural $\mathrm{CO}_{2}$ gradient. Conservation physiology, 4(1), $\operatorname{cov} 073$.

Cattano C, Calò A, Di Franco A, Firmamento R, Quattrocchi F, Sdiri K et al. (2017) Ocean acidification does not impair predator recognition but increases juvenile growth in a temperate wrasse off CO2 seeps. Marine environmental research, 132, 33-40.

Cattano C, Claudet J, Domenici P, Milazzo M (2018) Living in a high $\mathrm{CO}_{2}$ world: A global metaanalysis shows multiple trait-mediated fish responses to ocean acidification. Ecological monographs, 88(3), 320-335.

Clarke KR, Gorley RN (2006) User manual/tutorial. Primer-E Ltd., Plymouth, 93.

Coker DJ, Wilson SK, Pratchett MS (2014) Importance of live coral habitat for reef fishes. Reviews in Fish Biology and Fisheries, 24(1), 89-126.

Connell SD, Doubleday ZA, Foster NR, Hamlyn SB, Harley CD, Helmuth B et al (2018) The duality of ocean acidification as a resource and a stressor. Ecology, 99(5), 1005-1010.

Cornwall CE, Hurd CL (2015) Experimental design in ocean acidification research: problems and solutions. ICES Journal of Marine Science, 73(3), 572-581. 
De'ath G, Fabricius KE, Sweatman H, Puotinen M (2012) The 27-year decline of coral cover on the Great Barrier Reef and its causes. Proceedings of the National Academy of Sciences U.S.A., 109, 17995-17999.

Denis V, De Palmas S, Benzoni F, Chen CA (2015). Extension of the known distribution and depth range of the scleractinian coral Psammocora stellata: first record from a Taiwanese mesophotic reef. Marine Biodiversity, 45(4), 619-620.

Di Franco A, Calò A, Sdiri K, Cattano C, Milazzo M, Guidetti P (2019) Ocean acidification affects somatic and otolith growth relationship in fish: evidence from an in situ study. Biology letters, 15(2), 20180662.

Dickson AG (1990) Thermodynamics of the dissociation of boric acid in synthetic seawater from 273.15 to 318.15 K. Deep Sea Research Part A. Oceanographic Research Papers, 37(5), 755-766.

Dickson AG, Millero FJ (1987) A comparison of the equilibrium constants for the dissociation of carbonic acid in seawater media. Deep Sea Research Part A. Oceanographic Research Papers, 34(10), 1733-1743.

Enochs IC, Manzello DP, Donham EM, Kolodziej G, Okano R, Johnston L et al. (2015) Shift from coral to macroalgae dominance on a volcanically acidified reef. Nature Climate Change, 5, 10831088 .

Falkenberg LJ, Russell BD, Connell SD (2013) Contrasting resource limitations of marine primary producers: implications for competitive interactions under enriched $\mathrm{CO}_{2}$ and nutrient regimes. Oecologia 172, 575-583 (2013).

Fabricius KE, Langdon C, Uthicke S, Humphrey C, Noonan S, De'ath G et al. (2011) Losers and winners in coral reefs acclimatized to elevated carbon dioxide concentrations. Nature Climate Change, 1, 165-169

Fabricius KE, De'ath, G, Noonan S, Uthicke S (2014) Ecological effects of ocean acidification and habitat complexity on reef-associated macroinvertebrate communities. Proceeding of the Royal Society B: Biological Sciences, 281, 20132479

Filbee-Dexter K, Wernberg T (2018). Rise of turfs: A new battlefront for globally declining kelp forests. BioScience, $\mathbf{6 8}(2)$, 64-76.

Gaylord B, Kroeker KJ, Sunday JM, Anderson KM, Barry JP, Brown NE et al. (2015) Ocean acidification through the lens of ecological theory. Ecology, 96(1), 3-15

Goldenberg SU, Nagelkerken I, Marangon E, Bonnet A, Ferreira CM, Connell SD (2018) Ecological complexity buffers the impacts of future climate on marine consumers. Nature Climate Change, $\mathbf{8}$, 229-233.Hall-Spencer JM, Rodolfo-Metalpa R, Martin S, Ransome E, Fine M, Turner SM et al. (2008) Volcanic carbon dioxide vents show ecosystem effects of ocean acidification. Nature, 454, 96-99.

Hall-Spencer JM, Harvey BP (2019) Ocean acidification impacts on coastal ecosystem services due to habitat degradation. Emerging Topics in Life Sciences, 3(2), 197-206.

Harley CD, Anderson KM, Demes KW, Jorve JP, Kordas RL, Coyle TA, Graham MH (2012) Effects of climate change on global seaweed communities. Journal of Phycology, 48(5), 1064-1078. 

Evaluation visuelle des peuplements et populations de poissons méthodes et problèmes.

Harvey BP, Gwynn-Jones D, Moore PJ (2013) Meta-analysis reveals complex marine biological responses to the interactive effects of ocean acidification and warming. Ecology and evolution, 3(4), 1016-1030.

Harvey BP, Agostini S, Kon K, Wada S, Hall-Spencer JM (2019) Diatoms Dominate and Alter Marine Food-Webs When $\mathrm{CO}_{2}$ Rises. Diversity, 11(12), 242.

Hoegh-Guldberg O (1999) Climate change, coral bleaching and the future of the world's coral reefs. Marine and freshwater research, 50(8), 839-866.

van Hooidonk R, Maynard JA, Manzello D, Planes S (2014). Opposite latitudinal gradients in projected ocean acidification and bleaching impacts on coral reefs. Global Change Biology, 20, 103112.

Hughes TP (1994) Catastrophes, phase-shifts, and large scale degradation of a Caribbean coral reef. Science, 265, 1547-1551.

Hurlbert SH (1984) Pseudoreplication and the design of ecological field experiments. Ecological monographs, 54(2), 187-211.

Inoue S, Kayanne H, Yamamoto S, Kurihara H (2013) Spatial community shift from hard to soft corals in acidified water. Nature Climate Change, 3, 683-687.

Jackson JBC, Kirby MX, Berger WH et al. (2001) Historical Overfishing and the Recent Collapse of Coastal Ecosystems. Science, 293, 629-637.

Kroeker KJ, Kordas RL, Crim R, Hendriks IE, Ramajo L, Singh GS, Duarte CM, Gattuso JP (2013) Impacts of ocean acidification on marine organisms: quantifying sensitivities and interaction with warming. Global Change Biology, 19(6), 1884-1896.

Kumagai NH, Molinos JG, Yamano H, Takao S, Fujii M, Yamanaka Y (2018) Ocean currents and herbivory drive macroalgae-to-coral community shift under climate warming. Proceedings of the National Academy of Sciences, 115(36), 8990-8995.

Legendre P, Anderson MJ (1999) Distance-based redundancy analysis: testing multispecies responses in multifactorial ecological experiments. Ecological monographs, 69(1), 1-24.

McArdle BH, Anderson MJ (2001) Fitting multivariate models to community data: a comment on distance-based redundancy analysis. Ecology, 82(1), 290-297.

McCulloch M, Fallon S, Wyndham T, Hendy E, Lough J, Barnes D (2003). Coral record of increased sediment flux to the inner Great Barrier Reef since European settlement. Nature, 421(6924), 727730.

Mehrbach C (1973) Measurement of the apparent dissociation constants of carbonic acid in seawater at atmospheric pressure.

Midorikawa T, Nemoto K, Kamiya H, Ishii M, Inoue H Y (2005) Persistently strong oceanic $\mathrm{CO}_{2}$ sink in the western subtropical North Pacific. Geophysical Research Letters, 32, L05612. 
Milazzo M, Cattano C, Alonzo SH, Foggo A, Gristina M, Rodolfo-Metalpa R et al. (2016) Ocean acidification affects fish spawning but not paternity at $\mathrm{CO} 2$ seeps. Proceedings of the Royal Society B: Biological Sciences, 283(1835), 20161021.

Milazzo M, Alessi C, Quattrocchi F, Chemello R, D'Agostaro R, Gil J et al (2019) Biogenic habitat shifts under long-term ocean acidification show nonlinear community responses and unbalanced functions of associated invertebrates. Science of The Total Environment, 667, 41-48.

Mouillot D, Graham NA, Villéger S, Mason NW, Bellwood DR (2013) A functional approach reveals community responses to disturbances. Trends in ecology \& evolution, 28(3), 167-177.

Muir PR, Wallace CC, Done T, Aguirre JD (2015) Limited scope for latitudinal extension of reef corals. Science, 348, 1135-1138.

Munday PL, Cheal AJ, Dixson DL, Rummer JL, Fabricius KE (2014) Behavioural impairment in reef fishes caused by ocean acidification at $\mathrm{CO}_{2}$ seeps. Nature Climate Change, 4, 1-6.

Nagelkerken I, Russell BD, Gillanders BM, Connell SD (2015) Ocean acidification alters fish populations indirectly through habitat modification. Nature Climate Change, 6, 89 - 95.

Nagelkerken I, Goldenberg SU, Ferreira CM, Russell BD, Connell SD (2017) Species interactions drive fish biodiversity loss in a high- $\mathrm{CO}_{2}$ world. Current Biology, 27(14), 2177-2184.

Nakamura Y, Feary DA, Kanda M, Yamaoka K (2013) Tropical fishes dominate temperate reef fish communities within western Japan. PloS ONE, 8, e81107.

O'Brien JM Scheibling RE (2018) Turf wars: competition between foundation and turf-forming species on temperate and tropical reefs and its role in regime shifts. Marine Ecology Progress Series, 590, 1-17.

Pierrot D, Lewis E, Wallace DWR (2006) MS Excel Program Developed for $\mathrm{CO}_{2}$ System Calculations. ORNL/CDIAC-105a. Carbon Dioxide Information Analysis Center, Oak Ridge National Laboratory, U.S. Department of Energy, Oak Ridge, Tennessee. doi: 10.3334/CDIAC/otg.CO2SYS_XLS_CDIAC105a.

Pratchett MS, Hoey AS, Wilson SK, Messmer V, Graham NA (2011) Changes in biodiversity and functioning of reef fish assemblages following coral bleaching and coral loss. Diversity, 3(3), 424452.

R Core Team 2018 R: A Language and Environment for Statistical Computing. R Foundation for Statistical Computing, Vienna, Austria.

Rastrick SS, Graham H, Azetsu-Scott K, Calosi P, Chierici M, Fransson A et al (2018) Using natural analogues to investigate the effects of climate change and ocean acidification on Northern ecosystems. ICES Journal of Marine Science, 75(7), 2299-2311.

Rodolfo-Metalpa R, Houlbrèque F, Tambutté E, Boisson F, Baggini C, Patti FP, Jeffree R et al. (2011) Coral and mollusc resistance to ocean acidification adversely affected by warming. Nature Climate Change, 1, 308-312.

Schneider CA, Rasband WS, Eliceiri KW (2012) NIH Image to ImageJ: 25 years of image analysis. Nature methods, 9(7), 671. 
Serrano E, Coma R, Ribes M, Weitzmann B, García M, Ballesteros E (2013) Rapid northward spread of a zooxanthellate coral enhanced by artificial structures and sea warming in the western Mediterranean. PLoS One, 8(1), e52739.

Smith JN, De'ath G, Richter C, Cornils A, Hall-Spencer JM, Fabricius KE (2016) Ocean acidification reduces demersal zooplankton that reside in tropical coral reefs. Nature Climate Change, 6, 11241129

Stewart-Oaten A, Murdoch WW, Parker KR (1986) Environmental impact assessment: “pseudoreplication"' in time? Ecology, 67, 929-940

Suggett DJ, Hall-Spencer JM, Rodolfo-Metalpa R, Boatman TG, Payton R, Tye Pettay D et al. (2012) Sea anemones may thrive in a high $\mathrm{CO}_{2}$ world. Global Chang Biology, 18, 3015-3025

Sunday JM, Fabricius KE, Kroeker KJ, Anderson KM, Brown NE, Barry JP et al (2017) Ocean acidification can mediate biodiversity shifts by changing biogenic habitat. Nature Climate Change, $7(1), 81$.

Tuckett CA, de Bettignies T, Fromont J, Wernberg T (2017) Expansion of corals on temperate reefs: direct and indirect effects of marine heatwaves. Coral Reefs, 36(3), 947-956.

Uppström L R (1974) The boron/chlorinity ratio of deep-sea water from the Pacific Ocean. Deep-Sea Research and Oceanographic Abstracts, 21, 161-162.

Vergés A, Steinberg PD, Hay ME, Poore AGB, Campbell AH, Ballesteros E et al. (2014) The tropicalization of temperate marine ecosystems: climate-mediated changes in herbivory and community phase shifts. Proceeding of the Royal Society B: Biological Sciences, 281, 20140846

Vergés A, Doropoulos C, Malcolm HA, Skye M, Garcia-Pizá M, Marzinelli EM et al. (2016) Longterm empirical evidence of ocean warming leading to tropicalization of fish communities, increased herbivory, and loss of kelp. Proceedings of the National Academy of Sciences U.S.A., 201610725.

Veron JEN, Minchin PR (1992) Correlations between sea surface temperature, circulation patterns and the distribution of hermatypic corals of Japan. Continental Shelf Research, 12(7-8), 835-857.

Viechtbauer W (2010) Conducting meta-analyses in $\mathrm{R}$ with the metafor package. Journal of Statistical Software, 36(3), 1-48.

Vizzini S, Di Leonardo R, Costa V, Tramati CD, Luzzu F, Mazzola A (2013) Trace element bias in the use of $\mathrm{CO}_{2}$ vents as analogues for low $\mathrm{pH}$ environments: Implications for contamination levels in acidified oceans. Estuarine, Coastal and Shelf Science, 134, 19-30.

Vizzini S, Martínez-Crego B, Andolina C, Massa-Gallucci A, Connell SD, Gambi MC (2017) Ocean acidification as a driver of community simplification via the collapse of higher-order and rise of lower-order consumers. Scientific reports, 7(1), 4018.

Wilson SK, Burgess SC, Cheal AJ, Emslie M, Fisher R, Miller I et al (2008a) Habitat utilization by coral reef fish: implications for specialists vs. generalists in a changing environment. Journal of Animal Ecology, 77(2), 220-228. 

and habitat degradation as agents of change within coral reef fish communities. Global Change Biology, 14, 2796-2809

Wittmann AC, Pörtner HO (2013) Sensitivities of extant animal taxa to ocean acidification. Nature Climate Change, 3(11), 995.

Wood SN (2006) Low-rank scale-invariant tensor product smooths for generalized additive mixed 601 models. Biometrics, 62(4), 1025-1036.

602 Wood SN (2011) Fast stable restricted maximum likelihood and marginal likelihood estimation of semiparametric generalized linear models. Journal of the Royal Statistical Society: Series B 604 (Statistical Methodology), 73(1), 3-36.

605 Yamano H, Sugihara K, Nomura K (2011) Rapid poleward range expansion of tropical reef corals in 606 response to rising sea surface temperatures. Geophysical Research Letters, 38(4).

607 Yara, Y, Vogt M, Fujii M, Yamano H, Hauri C, Steinacher M et al. (2012) Ocean acidification limits 608 temperature-induced poleward expansion of coral habitats around Japan. Biogeosciences, 9, 49556094968.

610 Zarco-Perello S, Langlois TJ, Holmes T, Vanderklift MA, Wernberg T (2019) Overwintering tropical 611 herbivores accelerate detritus production on temperate reefs. Proceedings of the Royal Society B, $612 \quad$ 286(1915), 20192046. 

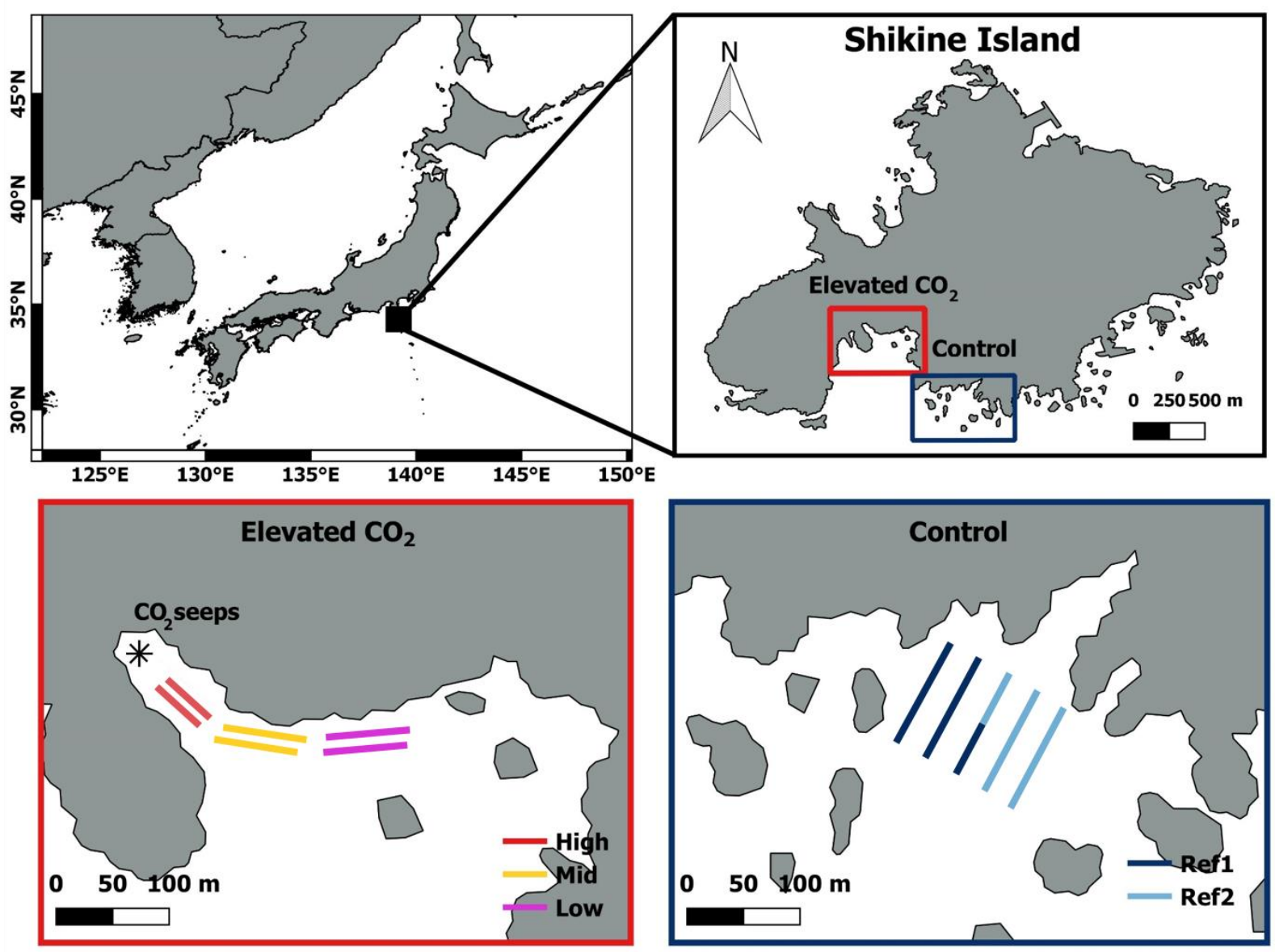

614

615 Figure 1 -Map of the study showing Shikine Island, the two $\mathrm{CO}_{2}$ locations (Elevated and Control) and 616 the five $\mathrm{CO}_{2}$ sites (High, Mid, Low, Refl and Ref2) where the benthic and fish 25m-transects were 617 positioned. 


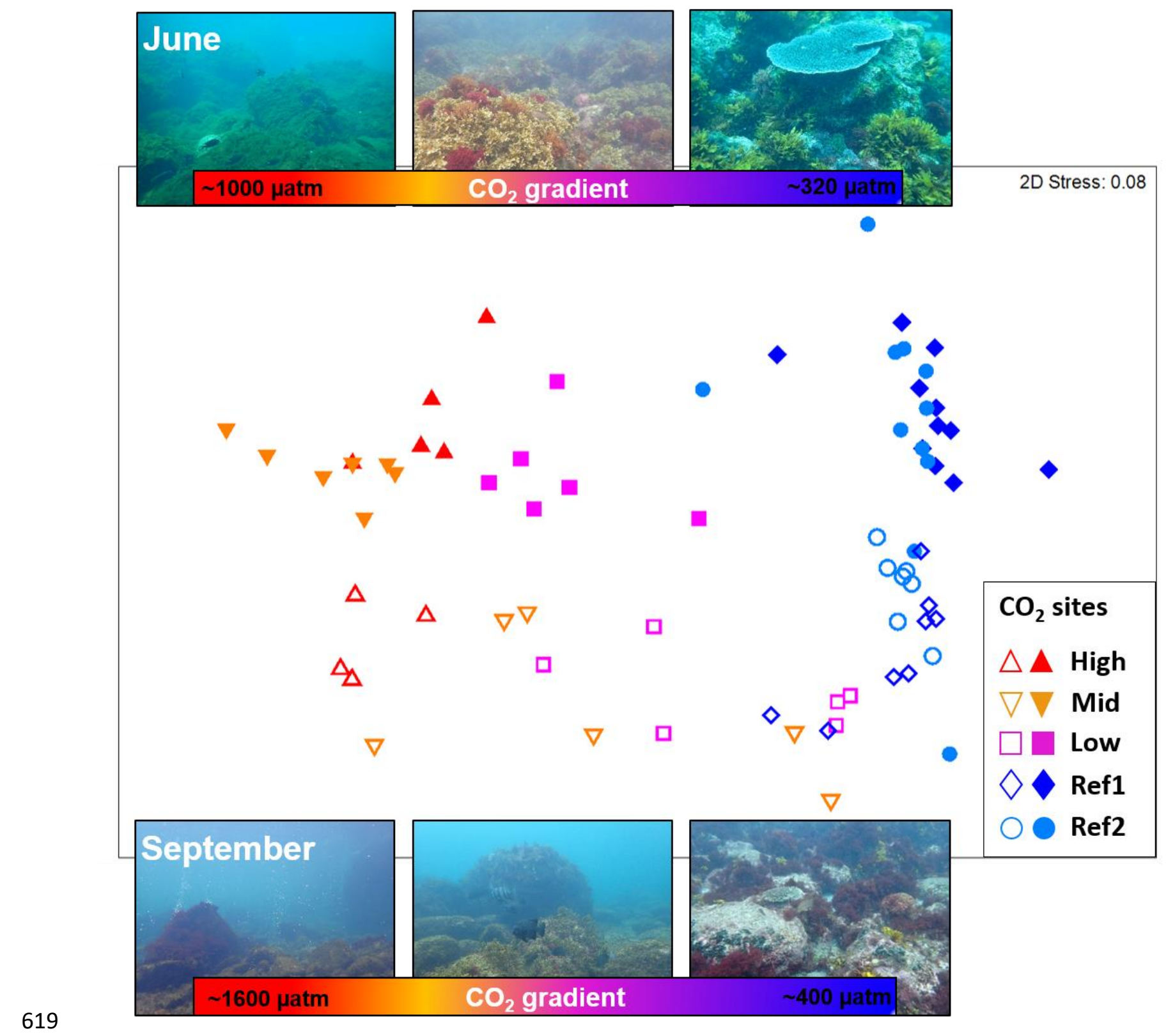

620 Figure 2 - Non-metric multidimensional scaling (nMDS) on benthic habitats at the five $\mathrm{CO}_{2}$ sampling 621 sites (High, Mid, Low, Ref1 and Ref2) in June (filled symbols) and September (empty symbols). 622 Photomosaics of benthic community shifts observed in June and September along the $\mathrm{CO}_{2}$ gradient are 623 also reported. The figure shows a clear community shifts in both seasons from zooxanthellate 624 scleractinian corals and canopy-forming macroalgae at Control $\mathrm{CO}_{2}$ location (Ref1 and Ref2) to 625 macroalgae at the Low and Mid $\mathrm{CO}_{2}$ sites and turf algae at the High $\mathrm{CO}_{2}$ site. 


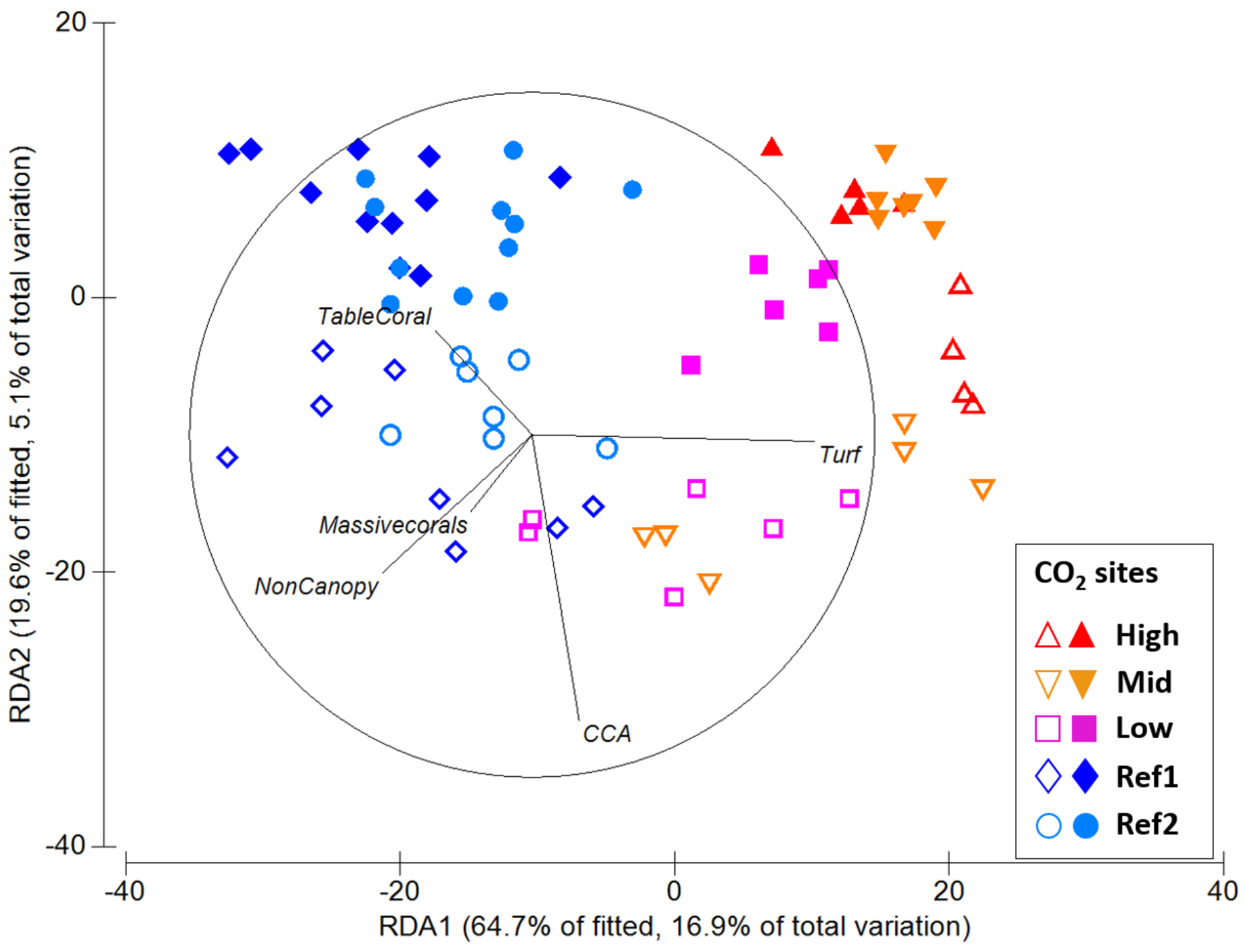

628 Figure 3-dbRDA ordination of fish community data from five sampling sites (High, Mid, Low, Ref1 and 629 Ref2) constrained by five environmental variables (CCA, Massive corals, table corals, Turf and non 630 canopy algae) identified by DISTLM as significant in explaining 84,3\% of fitted and $22 \%$ of total 631 variation. Vectors represent strength of variables in the model. Their length in relation to the circle 632 radius (radius $=1.0$ ) and their direction indicate the strength and the sign, respectively, of the 633 relationship between the variable and the axes. Filled and empty symbols represent data from June and 634 September, respectively.

635 
a)

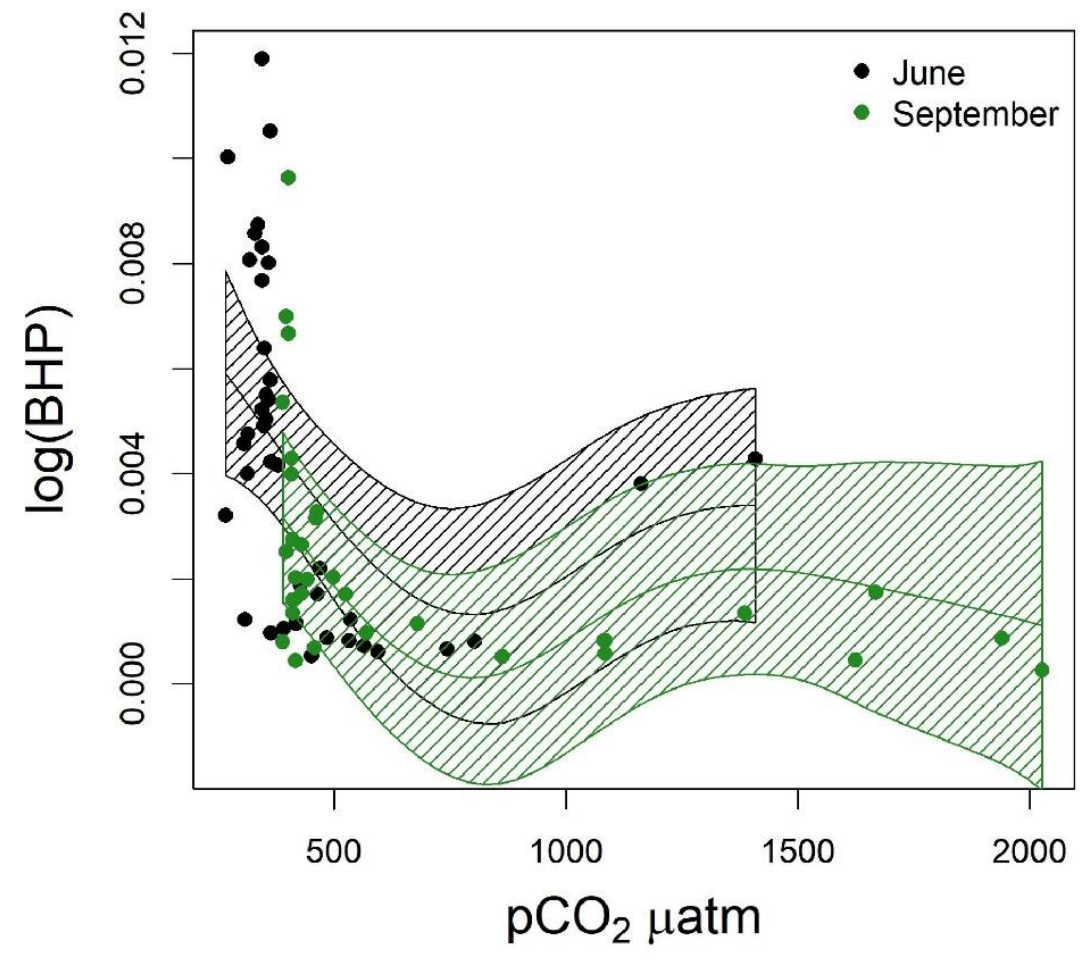

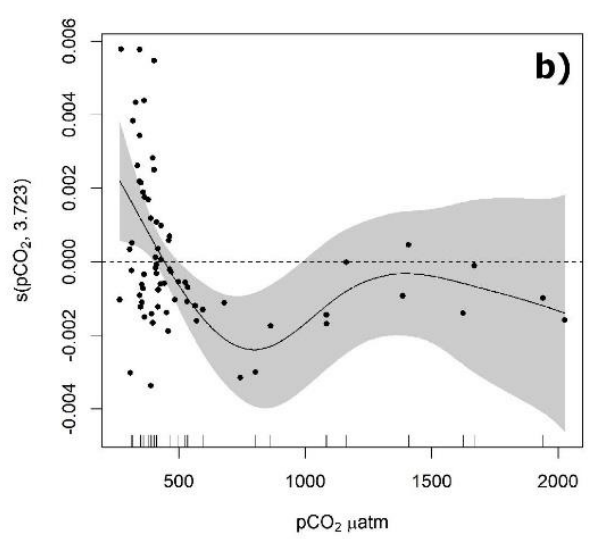

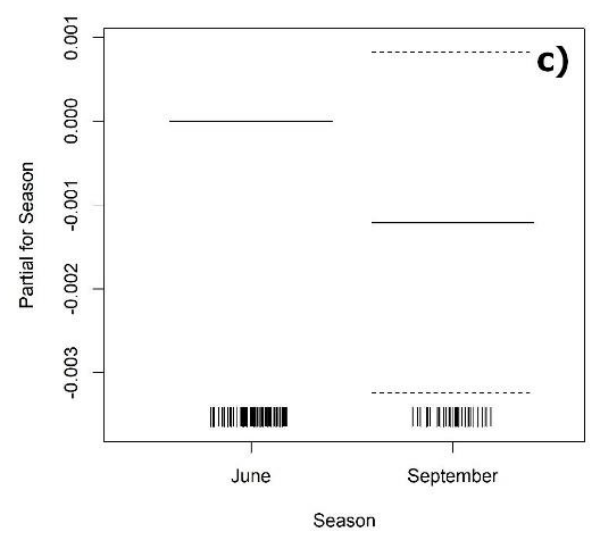

636

637 Figure 4-AMM (Additive Mixed Model) showing the relationship between $\mathrm{pCO}_{2}$ values and habitat 638 complexity (BHP). a) Fitted values ( $\pm 95 \%$ confidence intervals) of $\mathrm{pCO}_{2}$ values and habitat complexity 639 (log-transformed BHP index) for June (black dots) and September (green dots); b) model residuals 640 (black dots) and estimated smoothing curve (solid line with $\pm 95 \%$ confidence interval) showing the $\mathrm{pCO}$ 641 effects on BHP. The effect is significant (i.e. positive or negative) when the CI (grey area) does not 642 overlap the zero (dashed line); c) partial effect (solid lines) of the factor Season on the BHP index 643 (dashed lines indicate the $\pm 95 \%$ confidence interval for September). The vertical lines reported on the $644 x$-axis of panels $b$ and $c$ represent the observations from the different $\mathrm{pCO}_{2}$ values and from the two 645 seasons, respectively. 
Species richness and abundance (all species)

a)

Number of Species _ _ Abundance of species
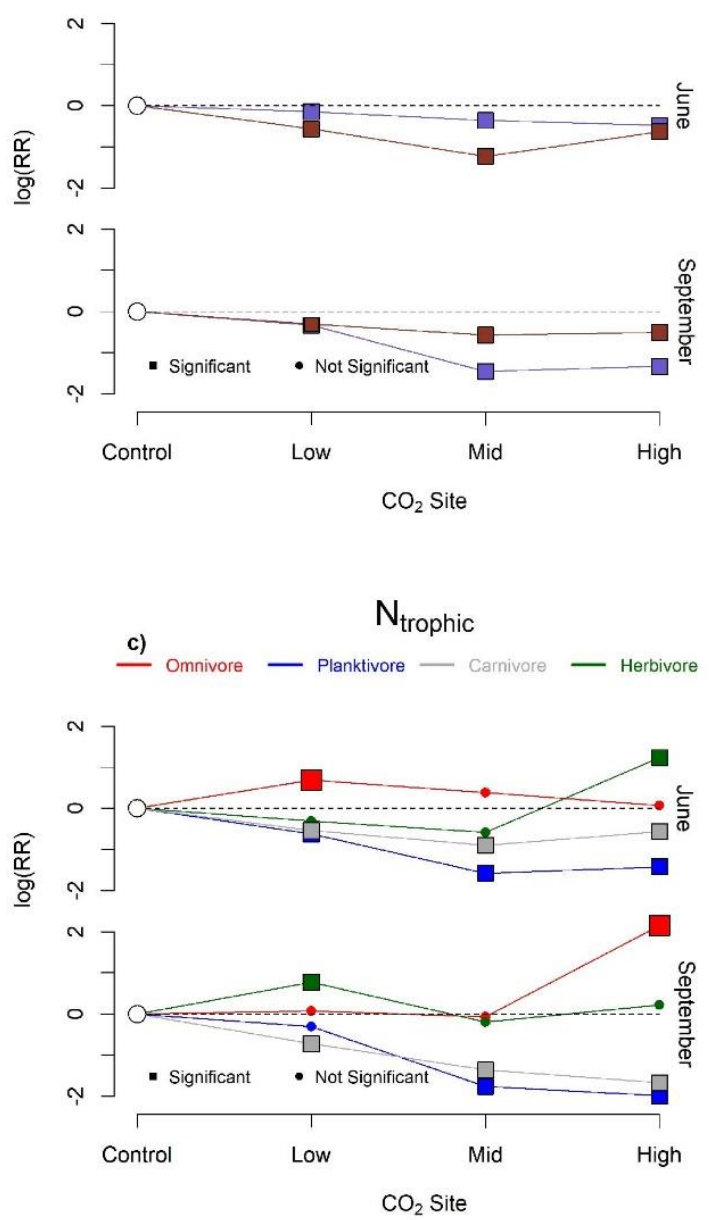
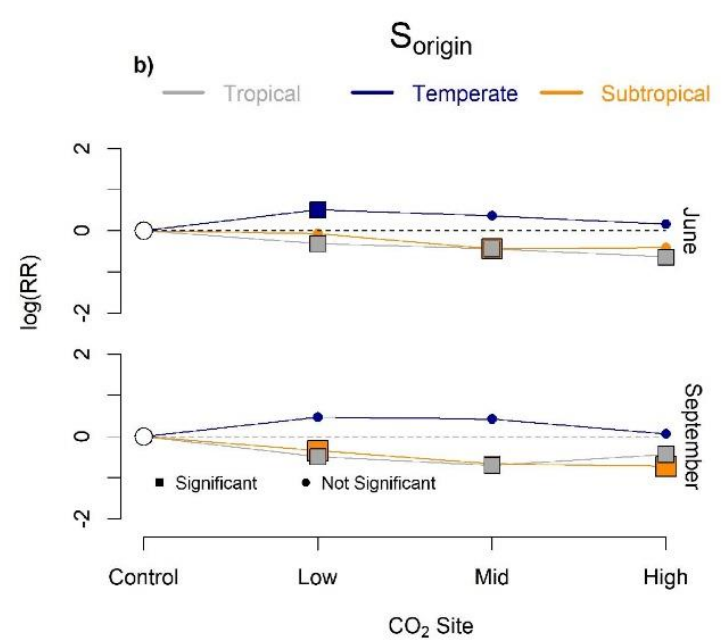

d)

$\mathrm{S}_{\text {coral }}$
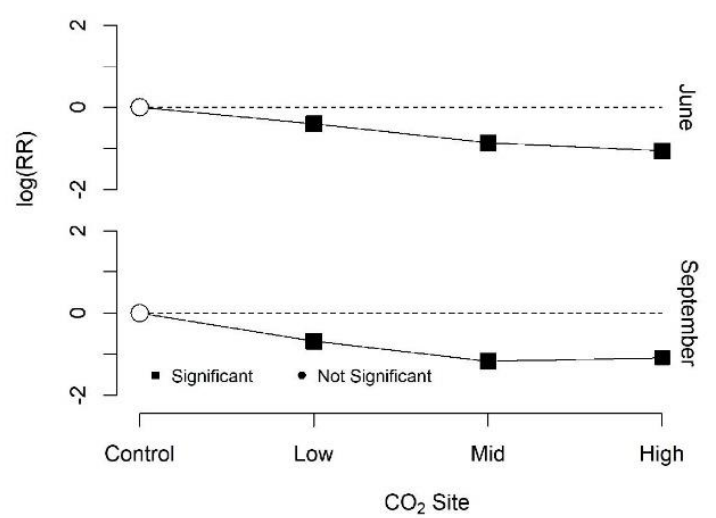

647

648

649

650

651

652

653

654

655

656

Figure 5 - Meta-analysis-derived approach to assess overall and trait-based changes of fish community at the different elevated $\mathrm{CO}_{2}$ sites, both in June and September. Each point represents the log response ratio (LnRR) of the average value for the different fish community variables recorded at Low, Mid and High $\mathrm{CO}_{2}$ sites relative to the ambient $\mathrm{CO}_{2}$ condition (i.e. Control location: Refl and Ref2 together), indicating the sign and the strength of change. a) Number and abundance of fish species (all the censused species); b) Sorigin: number of species by their geographic distribution (Tropical, Sub-tropical or Temperate); c) Ntrophic: abundance of species by their trophic guild (Omnivore, Planktivore, Carnivore or Herbivore); d) $S_{\text {coral: }}$ number of coral-reef associated fish species. Squares indicate significant effects per $p<0.05$. Small circles indicate no significant differences. 